\title{
Impedance Problem Identified
}

National Cancer Institute

\section{Source}

National Cancer Institute. Impedance Problem Identified. NCI Thesaurus. Code C92063.

Problems due to insufficient or excessive resistance to current flow either by the device or circuit. 